\title{
Gender and Development Mainstreaming Practices and Issues: Promoting Socialization and Development at Higher Education
}

\author{
Birhanu Moges Alemu (PhD) \\ Arsi University College of Education and Behavioral Sciences Department of Psychology
}

\begin{abstract}
Gender imbalance in different sectors is one of the current critical issues that requires immediate intervention and empowerment of females in decision making and implementation of affirmative action to correct it. The main objective of this study is to examine development and gender socialization mainstreaming issues at higher education. This study is a case study research designs undertaken using quantitative and qualitative methods, in which the university community (staff and students of both sexes) participated. The results of this study indicated that university related issues such as rules and regulations, peer pressure, lack of female role models, department choice of students and providing different supportive trainings by the university impacts females' socialization and development. Specifically, results indicated that females are: more likely than men to attribute success to hard work or luck rather than skill; more likely to blame themselves for a lack of success than are male; tend to feel less comfortable in public debate; more likely to be interrupted when they speak; more likely to phrase their comments in a hesitant manner; and less likely than male students to shape the agenda of the discussion. The problems most frequently cited were violence, harassment and lack of security. This study strongly suggests that in order to improve gender development and socialization, attention should be given to personal security, material support and assertiveness creation. Therefore, ministry of education, university and community should give due attention to promote females socialization and development.
\end{abstract}

Keywords: Development, gender, higher education, mainstream, practices, socialization.

\subsection{Background of the study}

\section{Introduction}

The natural environment does not distinguish males and females. However, whenever the exposure of human beings to the natural environment occurred, both sexes started to differ in the nature and depth of their experiences. Later, the gender disparity that began in a small way, get widened by political, economic, cultural and other factors[13]. Education is one of the social factors where by gender disparity is reflected. In the field of education, the number of educated females is very low. As the grade level in school increases, the number of female students starts to decline because of lots of factors ([17, 25]). The idea that gender is learned through socialization is ubiquitous in sociological literature on gender; the prevalent sociological viewpoint generally rejects biologically deterministic explanations for differences in gender and gendered behavior $[4,13]$.

Gender socialization and development have a broad and varied literature [8]. Research on gender socialization in childhood, adolescence, and adulthood consider different stages that are unique to human development. The focus for this discussion is based on how males and females learn masculinity and femininity through family/primary group interactions, and how they are socialized into dichotomous, "traditional" gender roles. Specifically, the idea that males learn masculinity and masculine impressions in opposition to femininity and feminine behavior is examined. These mechanisms of socialization are examined as identity processes that the family and other primary groups help to create and maintain.

Consequently, higher intuitions: remains an area of learning from which women are less represented. The very few women that are fortunate enough to join higher institutions are characterized by lower academic performance and higher forced withdrawal. As a result, such inequity in higher intuitions representation has a serious lifelong impact on their opportunities to participate in the country's political power sharing, economic privileges as well as social representations. This is because, currently, joining higher education has become a path to upward social mobility status, political power, economic privilege and social prestige [17].

Different people put different meanings to the concept gender. It describes the differences between women and men which are based on socially defined ideas and beliefs of what it means to be a man or a woman. It is important to note that sex refers to a person's biological makeup and gender describes their social definition. Gender is thus culturally constructed and gender roles are socially prescribed and not given by nature. Gender is thus one's social identity. Gender as an interdisciplinary concept refers to women and men, the relations between them, and the institutions that govern these relations. 
Gender equality is the ability of men and women, boys and girls to enjoy the same status and have equal opportunity to realize their potential to contribute to the wellbeing of their community and country at large. Gender equality according to [11] rests on five pillars namely: men and women have the same intrinsic value; men and women are equally valuable to society; men and women should have equal rights and responsibilities; there should be no discrimination on the grounds of gender; and equality needs not translate into sameness. [13] Equity as encompassing justice, equality, humanity, morality and right. They go on say that the goal of equality is a basic standard against which equity is judged. Thus gender equity is more than just equality as it is founded on the precepts of justice. Whereas equality conveys an element of prescription and measurability [13], equity according to [22] is founded not on any principle of beneficience, benevolence or charity but upon right. Thus gender equity has a broader meaning and greater implication than gender equality.

Gender and sustainable development is the current international approach to advancing gender equality and equity in society. With regard to this, the [26] noted that at the level of national government, gender and sustainable development involves incorporating a gender perspective into all policies, plans, programs and projects to ensure that these impact on women and men in an equitable way. Moreover, men's and women's empowerment and their full participation on the basis of equality in all spheres of society are fundamental for the achievement of sustainable development [16]. In relation to this, Hendricks and Oder (2010), argued that the principle of integrating men and women equally in the development process both as participants in planning, policy making and as beneficiaries has now become widely accepted by governments throughout the world.

Sustainable development requires the full and equal participation of women at all levels. Women's rights are universal human rights and are protected by international human rights conventions. Also, it is clearly inappropriate to try and address problems, to identify the appropriate strategies, or to implement the solutions if only half of the people concerned are involved in the process. Gender equity is an essential building block in sustainable development. Indeed, none of the three "pillars" of sustainable development can be achieved without solving the prevailing problem of gender inequity $[9,11,26]$ :

- Environmental protection requires a solid understanding of women's relationship to environmental resources, as well as their rights and roles in resource planning and management. It also requires acknowledgement and incorporation of women's knowledge of environmental matters, as well as an understanding of the gender specific impacts of environmental degradation and misuse [26];

- Economic well-being requires gender-sensitive strategies. Seventy of the world's estimated 1.3 billion people living in absolute poverty are women. Segmentation of labour markets - horizontally and vertically has only marginally improved [26]. Economic well-being of any society cannot be achieved if one group is massively underprivileged compared to the other. Nor can an economy be called healthy without utilising the contributions and skills of all members of society [15];

- Social equity is fundamentally linked to gender equity. Sexism, racism, discrimination on the grounds of ethnic group, faith, political opinion, social status or sexual orientation is clear indicators of social inequity. No society can survive sustainably, or allow its members to live in dignity, if there is prejudice and discrimination of any social group [26].

The problem for women's education is not obtaining the advantages that education can offer. Currently, female enrollments are significantly improving from time to time. But gender disparities still exist in education participation and performance in each year of higher institutions. Factors that are hindering female socialization, development and participation in higher institutions appear to exist [12]. Some females clearly do enter tertiary institutions despite numerous obstacles, but for most females, the battles to overcome gender impediments and obtain qualifications once they are enrolled continue unabated [27].They often encounter an institutional culture that has not been transformed and that remains hostile to their gender needs. Within this culture, they either negotiate their specific needs as discretely and unobtrusively as possible, or dropout when the environment makes trend and causes of female students' dropout. Their requirements may vary from the need for child care from parents, the need for females' residences, for safe and accessible transport to and from educational institutions at all hours, to an institutional culture which values females' intellectual capacities and skills. In order to ensure that every female enjoys her fundamental right to education, health, nourishment, political participation, legal rights, equal pay for equal work, different strategies and intervention programs were developed and implemented by the government of Ethiopia [17, 27]. The international community [18] has, among others, identified the following priority issues, providing an important framework for achieving gender equality in sustainable development: Women's human rights and control over their lives; poverty eradication; women's access to, control and management of resources and services; the impacts of globalisation; finance for development; and health, including reproductive and environmental health. Further, Ethiopia has been part of this global movement in support of the advancement of gender equality and equity. 
However, [13] argued that the speed with which these are put in practice to ensure women's and men's equal access to resources, opportunities and treatment, so critical to equitable, participatory and sustainable development has not been as expected. In the same framework, [12] supports the above explanation in such a way that although the fact that men and women are always assumed to be part of the development process, the latter have sometimes remained invisible to development planners and policy makers. Different sources [24] explained that gender inequality is one of the features of Ethiopian society. As a result, there is unequal power and economic relation between women and men. In almost all spheres of life, women are more disadvantaged than men. To address gender mainstreaming in development plans or programs is, therefore, not only about equity but also about social justice; it is also about development and poverty reduction [19].

\subsection{Statement of the Problem}

Global statistics place women behind men in relation to health, education, nutrition levels, political participation, legal rights, equal pay for equal work, amongst many other aspects of life [26]. Gender inequity remains pervasive in all countries of the world. This is both of public concern but also tied to individual behaviour. Generally, the obstacles to women's full participation in sustainable development and in public life can be grouped into three categories [11]: Constitutional factors, including legal and administrative areas, cultural, social, psychological and behavioural factors, economic factors, including access to and ownership of resources.

Ethiopian governments committed to a number of targets including a general target on gender equality, but also targets towards: elimination of gender disparity (in primary and secondary education); the empowerment of women; as well as assessment of commitments from past and ongoing international processes, and so on [16]. Whilst these commitments suggest increased international recognition of the importance of gender equity, it seems that Adama Science and Technology University faced by continued inequity in many schools and departments in a number of areas.

Gender socialization and development, which has been institutionalised within the notion of gender mainstreaming. Mainstreaming involves ensuring that a gendered perspective is central to all activities, including planning, implementation and monitoring of all programmes, projects, and legislation. While critiqued if undertaken merely as a 'tick box' exercise, gender mainstreaming offers a potential for placing gender at the heart of development. However, females' 'rights', particularly sexual and reproductive health rights, are not universally accepted as rights, and violence against females remains prevalent across the globe, and females still lack full and equal participation in economic and political life. Mainstreaming has yet to succeed and there is a need for a continued prioritisation of integrating females into development.

In the contemporary developing societies like Ethiopia, the length and breadth of human problems have become deeper. A study conducted on 'Gender, Development and Migration Linkages in Ethiopia' indicated that issues like gender inequalities, marginality, underdevelopment and respect for human rights are coming to be the major concerns of policy makers, administrators and the society at large [1]. However, gender structures in different government ministries or bureaus in Ethiopia in general and in Adama Science and Technology University in particular have not had the necessary human resource to target the issue [17]. The same source further revealed that in some bureaus experts have been assigned on top of their own responsibilities and in some others there is only one person to follow the whole activity. This implies that without having proper institutional structure it will be difficult to integrate the issue of gender in development programs.

A critical analysis of the gender and sustainable development in Adama Science and Technology University indicates that several factors contribute to genders' increased vulnerability to societal problems and to the failure of the current promotion interventions to have impact on the social determinants of the region among female and male participation. Among others, constructions of women and men appear to have important implications for Adama Science and Technology University.

Though a number of positive steps have been taken to address gender gaps in different socio-economic sectors in the country in general and in Adama Science and Technology University in particular, much has not been done in the area of gender and sustainable development activity particularly in government sectors. This being the case to researcher knowledge, no research attempt is made in the area of gender and sustainable development practice in government bureaus in Adama Science and Technology University. Hence, this study will addresses a small number of gender-sensitive issues that need to be taken into account by policy-makers and stakeholders working on solutions to the urgent economic, political, social, and environmental problems women face. The range of women/ gender and sustainable development issues is much wider; in fact, the majority of sustainable development issues need a gender mainstreaming approach.

The ministry of education of Ethiopia is taking many measures to improve females' enrolment in the higher intuitions. As a result, the number of female enrolled in higher learning institutions is relatively increasing. Despite this fact, experiences of the researcher show that the dropout rate of female students in higher learning institutions is so high as compared with their male counter parts. Here, it seems clear that 
thought the ministry of education has tried to increase the enrollment of females in higher learning institutions in each year and in every semester the problem of female students' dropout at tertiary level seems worth stressing. Hence, the present study was undertaken to investigate the gender socialization and development issues or factors affecting females' socialization and development at higher intuitions level.

\subsection{Objectives of the Study}

The present study is designed to assess the gender socialization and development issues in Adama Science and Technology University; to reflect through a policy and practices lens by applying identity theory and identity control theory. Besides, the study has the following specific objectives:

- To identify the existing status of gender socialization and sustainable development practices in the Adama Science and Technology University;

- To examine the major factors/issues for gender socialization and sustainable development practices;

- To explore perception of students towards gender socialization and development practices;

- To examine how self-image and self-presentation influence gender socialization and sustainable development practice

Based on the objectives stated above the researcher formulated the following research questions:

1. What are the major factors/issues for gender socialization and sustainable development practice?

2. How do self-image and self-presentation influence gender socialization and sustainable development practice?

3. What are perception of students towards gender socialization and development?

4. What are the misconceptions issues regarding femaleness and maleness?

\subsection{Significance of the Study}

Gender equality, equity and women's empowerment are the third of the Millennium Development Goals, operationalised with reference to the elimination of gender disparity at all levels of education. Bringing about gender equality requires, however, the mainstreaming of gender throughout government and NGOs development programs or plans and in particular addressing the specific gender socialization and challenges to gender equality and equity existing in a given setting. Therefore, conducting research on socialization, mainstreaming, practices, opportunities and challenges of gender and sustainable development in selected university can be helpful in many ways. First, it can provide information about the issue of gender mainstreaming, socialization and practices for public sectors, NGOs and other stakeholders. Secondly, it will shed some light for those who are involved in policy making and planning processes and enable them to address problems related to gender inequalities. Thirdly, the study can serve as the basis upon which various specific studies on gender issues can be made. Finally, the results of the study will contribute something in the effort to achieve gender related MDGs in the country.

\section{Materials And Methods}

A research design is used to structure the research, to show how all the major parts of the research project are fitted together. Thus, a design provides the glue that holds the research project together [7]. In this study it was framed within a critical qualitative and quantitative research approaches under-laboured by critical realist ontology, the study was conducted using a case study research design. This study examines sociological facets of gender and gender socialization by applying identity theory and identity control theory to explain how gender stereotypes emerge and perpetuate throughout the human life course ([6]; [22]). While the etiology of gender and the causes of gendered behavior are difficult to study, these two variants of identity theory offer a sound theoretical framework that describes why gender ideals and stereotypes perpetuate, as well as how the socialization process operates internally. By employing identity theory and identity control theory to the study of gender, we can better conceive why gender identities seem to be so important for individuals, and why gender identities generally perpetuate across the life course after they are formed.

In this study, four types of data collection instruments was develop and utilize to increase the breadth of information obtained from the respondents of the study. That was collected using interviews (namely unstructured and semi structured), focused group discussion, questionnaire and document analysis for triangulation purposes. These data was gathered from students, teachers, management bodies, student's dean and council and gender office. Interviews allow person-to-person discussion that can lead to increased insight into people's thoughts, feelings and behavior on important issues [7].

Quantitative approach was also used for the purpose of using numeric explanation to describe respondents' response (female and male students' response on the questionnaires). Simple random sampling was employed to select samples from faculties and departments. In addition, purposive sampling was adopted to select samples from management bodies, student councils, proctors, student dean, and gender office and dropout female students for interview and focused group discussion. One hundred fifty students 
completed the questionnaire and 15 (management bodies, deans and council, gender office, proctors and dropout female students) were included in the interview.With regard to data analysis, soon after the completion of the fieldwork, data collected through various sources were recorded, code and transcribed according to their order of categories by the researcher. In other words the field notes will first checked for accuracy and completeness then record and code according to the themes of the study subjects. In view of that the data was type by using the word processor and then it was sortie and categorize into major themes for content analysis and interpreter to reach in the stage of the findings of the study. The quantitative data were analyzed using SPSS and qualitative data were analyzed by narration and summarization.

For ethical considerations, the researcher follows logical procedures in every stage of data collection processes. Accordingly, the subjects of the study and the respondents was introduced about the purpose of the study then inform consent from the respondents and responsible officials of the organizations cover by the study was obtained to discuss with and interview them about the subject under discussion. Therefore, on the basis of these ethical principles, efforts was made to get the verbal consent of the respondents and confidentiality would be assure and kept throughout the process of this research work.

\section{Results And Discussion}

The Ethiopian society is quite gendered. The questions raised by the researcher are: Is university really conscious of the seriousness of gender based discrepancies? Are university instructors' really conscious of the important role they can play in addressing these discrepancies? To what extent is university prepared to critically challenge culture in the Ethiopian context in order to unveil the real foundations of gender injustices and challenges in Ethiopia? In this study the responses given from respondents are not as such far from those misconceptions. [13] argues that in order to eliminate gender bias in higher education, it is important to foster gender sensitivity among students during the process of university education. It is imperative therefore that university considers the issue of gender, not just as a peripheral topic, but as a stand-alone subject where qualified personnel are employed to equip the teacher to handle gender issues correctly as they deal with students. University is a critical area in the creation of a gender just society.

\subsection{Results}

\subsubsection{Analysis on the Culture and Misconceptions Issues of Gender Equality}

Culture, during the socialization process, imparts some gendered misconceptions about males and females. It is these misconceptions that have to be allayed to unveil the truth about the physical, mental, emotional and psychological attributes of males and females. [20] says, "Over centuries societies all over the world have developed ideas about what it is to be a man or a woman. These resulted in the loss of some fundamental truths about the inherent make up of women and replaced them with distorted views."

A critical look at the culture shows some of these misconceptions. [21] in her doctoral dissertation found out the following about gendered misconceptions in the culture.

Table 1: Misconceptions about the physical and mental attributes of gender (male and female)

\begin{tabular}{|l|l|l|}
\hline No & Items & Items \\
\hline $\mathbf{1}$ & Assumed Male Physical Characteristics & Assumed Female Physical Characteristics \\
\hline 1.1 & Strong & Weak \\
\hline 1.2 & Fast in doing their things & Slow in doing things \\
\hline 1.3 & React urgently to important things & $\begin{array}{l}\text { Take their time. Do not take things with the urgency } \\
\text { they deserve }\end{array}$ \\
\hline 1.4 & $\begin{array}{l}\text { Concerned with constructive issues. Not } \\
\text { concerned with outward looks }\end{array}$ & Too smart. Concerned with trivial things \\
\hline 1.5 & Always occupied in constructive talk & Gossipers \\
\hline 1.6 & Gain humanness and maturity with age & Childish regardless of their age \\
\hline 1.7 & Proactive & Reactive \\
\hline $\mathbf{2}$ & Illusions about Male's intellectual makeup & Illusions about Female's intellectual makeup \\
\hline 2.1 & Good decision makers & Poor decision makers regardless of age \\
\hline 2.2 & Good judgment & Poor in making judgment \\
\hline 2.3 & Fast thinkers. Problem solvers & Slow thinkers. Poor at problem solving \\
\hline 2.4 & Rational & Irrational \\
\hline 2.5 & Visionaries. They think ahead. & Think of just the present \\
\hline 2.6 & Planners. Good strategists. & Do things in a rush \\
\hline 2.7 & Think before acting & Poor organizers \\
\hline 2.8 & Good organizers & Surface thinkers \\
\hline 2.9 & Insightful & \\
\hline
\end{tabular}


On the whole, the previous evidence indicates that men's behavior and attitudes toward women's misconception are likely to be affected by a range of factors (i.e. Technological progress, media exposure, wage gaps, sex ratio, and offspring's gender). Given the great influence that men exert on the economic development of women, those factors should be considered in the design of public policies addressed at improving women's well being.

Table 2: Misconceptions about the emotional and psychological attributes of gender (male and female)

\begin{tabular}{|l|l|l|}
\hline No & Items & Items \\
\hline $\mathbf{3}$ & $\begin{array}{l}\text { Illusions about male's emotional and } \\
\text { psychological makeup }\end{array}$ & $\begin{array}{l}\text { Illusions about female's emotional and } \\
\text { psychological makeup }\end{array}$ \\
\hline 3.1 & Emotionally strong & Cry over petty issues, emotionally weak \\
\hline 3.2 & Controlled by reason & Controlled by emotion rather than reason \\
\hline 3.3 & Principled & Less principled \\
\hline 3.4 & Cannot be easily controlled & Can be easily controlled \\
\hline 3.5 & Not very spiritual & Too spiritual \\
\hline 3.6 & Driven by a desire for success & Driven by a desire to please the husband \\
\hline 3.7 & Less need for affection & High need for affection \\
\hline $\mathbf{4}$ & Illusions about male's leadership attributes & Illusions about female's leadership attributes \\
\hline 4.1 & They were born to be leaders & They were born to be subordinates \\
\hline 4.2 & They have the ability to control subordinates & They cannot control subordinates \\
\hline 4.3 & They can make decisions which are binding & They cannot make sensible and binding decisions \\
\hline 4.4 & They are strategists & They cannot strategize \\
\hline 4.5 & They can withstand leadership pressures & They cannot withstand leadership pressure \\
\hline 4.6 & $\begin{array}{l}\text { Males are self sufficient as leaders so they can } \\
\text { lead without any problem }\end{array}$ & $\begin{array}{l}\text { Females need males to lead them in order for } \\
\text { them to function properly thus they cannot lead }\end{array}$ \\
\hline 4.7 & Males use facts in their leadership & Females depend on gossip in their leadership \\
\hline 4.8 & Males enter leadership though their ability & Females need men to enter leadership \\
\hline
\end{tabular}

$N B^{*}$ Tables $(1 \& 2)$ adapted from [21] doctoral thesis (PP, 221- 230)

These misconceptions are held as truth in some culture, thus they affect the perceptions of people on the ability of males and females. [21] postulates that cultural illusions are of interest to education because they are constraints that hinder the achievement of national goals and hinder the possibility for transformation. This then leads to problems like gender stereotyping, gender based socialization, gender based abuse in all its forms and language and discourse which reinforce these misconceptions. [4] Says, Culture and religion are the key factors in defining and regulating gender relations in most communities in Africa. All questions regarding the welfare and status of women in Africa are explained within the framework of culture. (p. 10)

[15] further notes that, Culture is the most important authoritative canon to the African worldview and any form of liberation will have to come to terms with culture. It is essential that African people learn how to question, examine and scrutinize culture. Such a process has a potential of opening the way for a critique of other systems - social, religious, economic and political. (p. 45)

The socialization process is the root of gender based challenges societies are facing today. Due to the gender based socialization, girls are socialized for a low status in life and boys are socialized for a higher status. [8] said that for girls this is done, "through restricting girls' activities to such an extent that their social development and exploration instincts are curtailed." This affects the girl's choices even in later life as a grown up woman. It is within such a framework that I find the Ethiopian higher education system enshrined.

\subsubsection{Students' perceptions toward gender socialization}

Twelve statements in the survey questionnaire were designed to assess students' perception toward gender socialization (Table 3). Respondents' perception regarding the gender Socialization activities were measured by statements 1-12 in the questionnaire. Many student respondents (65.3\%) believe instructors call on male students more frequently than female students; instructors are also more likely to use male students' names in attributing ideas advanced in discussion (62.4\%). A half of respondents perceived that instructors ask male students more abstract questions and female students more factual questions. About $59 \%$ of student respondents disagree in the statement "instructors are less likely to elaborate upon points made by female students." Similarly, most respondents (64.7\%) disagree on the statement "female students speak more frequently and longer in class discussions." However; many of the participants (64.8\%) considered in that male students are more likely to blurt out answers without raising their hands or being recognized by the instructor. Similarly, a large number of respondents $(62.7 \%)$ agree in that "female students are more likely to be interrupted before they complete their response." For the statement "female students express their ideas in a more hesitant, tentative, indirect and less assertive than male students" most respondent have positive attitude (68.7\%). From the data, about $79.4 \%$ strongly disagree and disagree that the statement "male students tend to make shorter and quieter statements than female students" them is unacceptable; whilst $74 \%$ strongly agree and agree to the statement 
"female students accompany their statements with smiles eyes rather than more assertive gestures" about their self esteem. In a similar manner, the analysis for statement "female students are less likely to raise their hands immediately in response to initial questions than male students", that is, the respondents indicated that $59.3 \%$ agree, whilst for the statement "female students are more likely to raise their hands immediately in response to initial questions than male students" $62.7 \%$ of respondent disagree with the arrangement. In this study, it is possible to reflect in that most female students are disadvantages in their university life.

Table 3: Students Perceptions towards Gender Socialization and Development

\begin{tabular}{|c|c|c|c|c|c|c|c|}
\hline \multirow[b]{2}{*}{ No } & \multirow{2}{*}{\multicolumn{2}{|c|}{ Factors/issues }} & \multicolumn{4}{|c|}{ Rating scale } & \multirow[b]{2}{*}{$\begin{array}{l}\text { Strongly } \\
\text { disagree }\end{array}$} \\
\hline & & & $\begin{array}{l}\text { Strongly } \\
\text { agree }\end{array}$ & Agree & Neutral & Disagree & \\
\hline 1 & $\begin{array}{l}\text { My instructors call on male students more frequently than } \\
\text { female students. }\end{array}$ & $\mathrm{N}$ & 25 & 98 & 5 & 14 & 8 \\
\hline \multirow[t]{2}{*}{2} & \multirow{2}{*}{$\begin{array}{l}\text { My instructors are more likely to use male students' } \\
\text { names in attributing ideas advanced in discussion. }\end{array}$} & $\mathrm{N}$ & 45 & 94 & 4 & 5 & 2 \\
\hline & & $\%$ & 30.7 & 62.4 & 2.7 & 3.3 & 1.3 \\
\hline 3 & $\begin{array}{l}\text { My instructors ask male students more abstract questions } \\
\text { and female students more factual questions. }\end{array}$ & $\mathrm{N}$ & 44 & 75 & 9 & 13 & 9 \\
\hline \multirow[t]{2}{*}{4} & \multirow{2}{*}{$\begin{array}{l}\text { My instructors are more likely to elaborate upon points } \\
\text { made by female students. }\end{array}$} & $\mathrm{N}$ & 8 & 7 & 28 & 89 & 18 \\
\hline & & $\%$ & 5.3 & 4.7 & 18.7 & 59.3 & 12.0 \\
\hline \multirow[t]{2}{*}{5} & \multirow{2}{*}{$\begin{array}{l}\text { Female students speak more frequently and longer in class } \\
\text { discussions than male students. }\end{array}$} & $\mathrm{N}$ & 4 & 7 & 20 & 97 & 22 \\
\hline & & $\%$ & 2.7 & 4.7 & 13.3 & 64.7 & 14.7 \\
\hline 6 & $\begin{array}{l}\text { Male students are more likely to blurt out answers without } \\
\text { raising their hands or being recognized by the instructor } \\
\text { than male students. }\end{array}$ & $\mathrm{N}$ & 48 & 97 & 1 & 4 & - \\
\hline \multirow[t]{2}{*}{8} & \multirow{2}{*}{$\begin{array}{l}\text { Female students express their ideas in a more hesitant, } \\
\text { tentative, indirect \&less assertive. }\end{array}$} & $\mathrm{N}$ & 25 & 103 & 14 & 6 & 2 \\
\hline & & $\%$ & 17.7 & 68.7 & 9.3 & 4.0 & 1.3 \\
\hline \multirow[t]{2}{*}{9} & \multirow{2}{*}{$\begin{array}{l}\text { Male students tend to make shorter and quieter statements } \\
\text { than female students. }\end{array}$} & $\mathrm{N}$ & 18 & 6 & 4 & 94 & 25 \\
\hline & & $\%$ & 12.0 & 4.0 & 2.7 & 62.7 & 16.7 \\
\hline \multirow[t]{2}{*}{10} & \multirow{2}{*}{$\begin{array}{l}\text { Female students accompany their statements with smiles } \\
\text { eyes rather than more assertive gestures }\end{array}$} & $\mathrm{N}$ & 20 & 101 & 10 & 13 & 6 \\
\hline & & $\%$ & 13.3 & 67.3 & 6.7 & 4.0 & 4.0 \\
\hline \multirow[t]{2}{*}{11} & \multirow{2}{*}{$\begin{array}{l}\text { Female students are less likely to raise their hands } \\
\text { immediately in response than male students }\end{array}$} & $\mathrm{N}$ & 33 & 89 & 3 & 17 & 8 \\
\hline & & $\%$ & 22.0 & 59.3 & 2.0 & 11.3 & 5.3 \\
\hline \multirow[t]{2}{*}{12} & \multirow{2}{*}{$\begin{array}{l}\text { Female students are more likely to raise their hands } \\
\text { immediately in response to initial questions than male } \\
\text { students }\end{array}$} & $\mathrm{N}$ & 20 & 10 & 4 & 97 & 19 \\
\hline & & $\%$ & 13.3 & 6.7 & 2.7 & 64.7 & 12.7 \\
\hline
\end{tabular}

\subsubsection{University related issues/factors}

Respondents were asked to give their overall agreement about university related issues/factors such as university administrative and academic rules and regulations, university climate, peer and student to teacher's relationship, student to parent relationship, different supportive trainings, guidance and counseling services, lack of female role model teachers and department choice of students. Majority of respondents agree about the effect of these issues/factors on students' gender socialization and development (Table 4).

Table 4: The effect of university related factors on genders' socialization and development

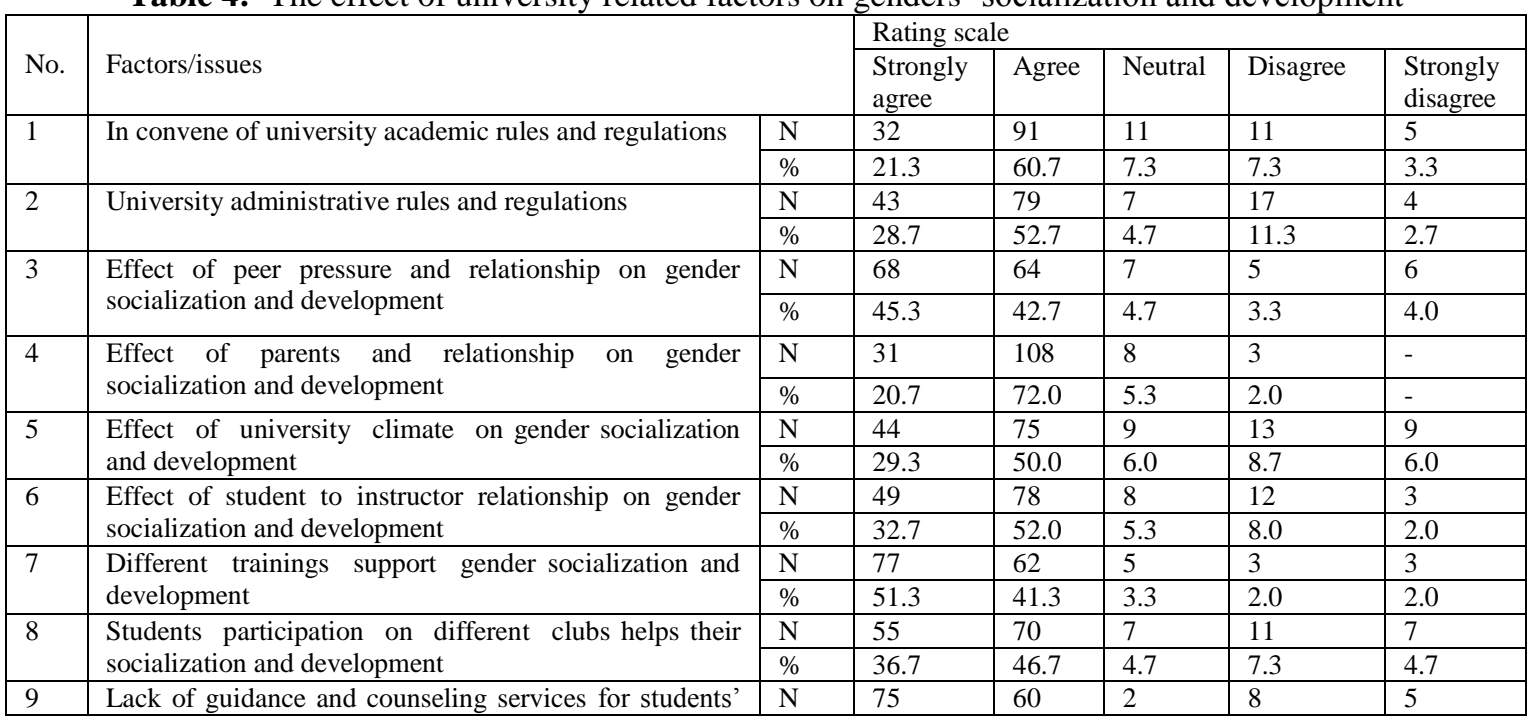


Gender and Development Mainstreaming Practices and Issues: Promoting Socialization and

\begin{tabular}{|l|l|l|l|l|l|l|l|}
\hline & socialization and development & $\%$ & 50.0 & 40.0 & 1.3 & 5.3 & 3.3 \\
\hline 10 & $\begin{array}{l}\text { Lack of female role model teachers for gender } \\
\text { socialization and development }\end{array}$ & $\mathrm{N}$ & 48 & 97 & 1 & 4 & - \\
\cline { 2 - 9 }
\end{tabular}

\subsubsection{Socio economic issues/factors}

As respondents' response socio economic issues/factors such as students' background area, economic status of parents, female students living outside University and being non café, limited employment opportunities and the presence and influx of tourists, expanding stimulators around the university gates and nearby, and night clubs/bars, widespread hotel beds around the university affect students socialization and development at higher education level (Table 5). Respondents also give their overall agreement about socio cultural factors affecting students' socialization and development. Such as self esteem/perception and level of parental education have an effect on students' socialization and development (Table 5).

Table 5: The effect of socio economic issues/factors on genders' socialization and development

\begin{tabular}{|c|c|c|c|c|c|c|c|}
\hline \multirow[b]{2}{*}{ No. } & \multirow{2}{*}{\multicolumn{2}{|c|}{ Factors/issues }} & \multicolumn{4}{|c|}{ Rating scale } & \multirow[b]{2}{*}{$\begin{array}{l}\text { Strongly } \\
\text { disagree }\end{array}$} \\
\hline & & & $\begin{array}{l}\text { Strongly } \\
\text { agree }\end{array}$ & Agree & Neutral & Disagree & \\
\hline \multirow[t]{2}{*}{1} & \multirow{2}{*}{\multicolumn{2}{|c|}{$\begin{array}{l}\text { Females who came from urban areas socialization better } \\
\text { than Females who came from rural areas }\end{array}$}} & $\mathrm{N}$ & 47 & 81 & 6 & 8 \\
\hline & & & $\%$ & 31.0 & 54.0 & 4.0 & 5.3 \\
\hline \multirow[t]{2}{*}{2} & \multirow{2}{*}{$\begin{array}{l}\text { Limited employment opportunities affect gender } \\
\text { socialization and development }\end{array}$} & $\mathrm{N}$ & 58 & 78 & 4 & 8 & 2 \\
\hline & & $\%$ & 38.7 & 52.0 & 2.7 & 5.3 & 1.3 \\
\hline \multirow[t]{2}{*}{3} & \multirow{2}{*}{$\begin{array}{l}\text { Economic status of parents affect female gender } \\
\text { socialization and development }\end{array}$} & $\mathrm{N}$ & 65 & 70 & 5 & 7 & 3 \\
\hline & & $\%$ & 43.3 & 46.7 & 3.3 & 4.7 & 2.0 \\
\hline \multirow[t]{2}{*}{4} & \multirow[t]{2}{*}{ Female and male students living outside the university } & $\mathrm{N}$ & 55 & 77 & 5 & 8 & 3 \\
\hline & & $\%$ & 45.3 & 51.3 & 3.3 & 5.3 & 2.0 \\
\hline \multirow[t]{2}{*}{5} & \multirow[t]{2}{*}{ Female and male students becomes non cafe } & $\mathrm{N}$ & 37 & 91 & 7 & 12 & 2 \\
\hline & & $\%$ & 24.8 & 60.7 & 4.7 & 8.0 & 2.0 \\
\hline \multirow[t]{2}{*}{6} & \multirow{2}{*}{$\begin{array}{l}\text { Presence of tourist centers around the university } \\
\text { affects gender socialization and development }\end{array}$} & $\mathrm{N}$ & 42 & 94 & 5 & 8 & - \\
\hline & & $\%$ & 87 & 51 & 3.3 & 5.3 & - \\
\hline \multirow[t]{2}{*}{7} & \multirow{2}{*}{$\begin{array}{l}\text { Presence of night clubs/ bars/ around the university } \\
\text { affects gender socialization and development }\end{array}$} & $\mathrm{N}$ & 77 & 62 & 3 & 5 & 3 \\
\hline & & $\%$ & 58.0 & 34.0 & 2.0 & 3.3 & 2.0 \\
\hline \multirow[t]{2}{*}{8} & \multirow[t]{2}{*}{ Female students self stem/perception } & $\mathrm{N}$ & 46 & 93 & 4 & 5 & 2 \\
\hline & & $\%$ & 30.7 & 62.0 & 2.7 & 3.3 & 1.3 \\
\hline \multirow[t]{2}{*}{9} & \multirow[t]{2}{*}{ Male students self stem/perception } & $\mathrm{N}$ & 46 & 93 & 4 & 5 & 2 \\
\hline & & $\%$ & 30.7 & 62.0 & 2.7 & 3.3 & 1.3 \\
\hline \multirow[t]{2}{*}{10} & \multirow[t]{2}{*}{ Level of parental education and experiences } & $\mathrm{N}$ & 66 & 65 & 8 & 6 & 3 \\
\hline & & $\%$ & 44.0 & 43.3 & 5.3 & 4.0 & 2.0 \\
\hline
\end{tabular}

\subsubsection{Gender differences in self-image and self-presentation}

Table 6 shows respondents' perceptions regarding their self-image and self-presentation. Statements 1-9 were designed to display the self-image and self-presentation related to gender socialization and development activities. Most of the participants (70.7\%) agreed that the female students are more likely than male to attribute success to hard work or luck rather than skill (Item1). The majority (76.0\%) also agreed that female students are more likely to blame themselves for a lack of success than are male students. While, $61.9 \%$ of respondents disagree on the statement "male students require higher grades to persist in a field than female students do." (Table 6)

Table 6: Students Perception towards Self-Image and Self-Presentation

\begin{tabular}{|c|c|c|c|c|c|c|c|}
\hline \multirow[t]{2}{*}{ No. } & \multirow{2}{*}{\multicolumn{2}{|c|}{ Factors/issues }} & \multicolumn{4}{|c|}{ Rating scale } & \multirow[b]{2}{*}{$\begin{array}{l}\text { Strongly } \\
\text { disagree }\end{array}$} \\
\hline & & & $\begin{array}{l}\text { Strongly } \\
\text { agree }\end{array}$ & Agree & Neutral & Disagree & \\
\hline \multirow[t]{2}{*}{1} & \multirow{2}{*}{$\begin{array}{l}\text { Female students are more likely than male to attribute } \\
\text { success to hard work or luck rather than skill. }\end{array}$} & $\mathrm{N}$ & 24 & 106 & 10 & 9 & 1 \\
\hline & & $\%$ & 16.0 & 70.7 & 6.7 & 6.0 & 0.7 \\
\hline \multirow[t]{2}{*}{2} & \multirow{2}{*}{$\begin{array}{l}\text { Male students require higher grades to persist in a field } \\
\text { than female students do. }\end{array}$} & $\mathrm{N}$ & 8 & 8 & 4 & 93 & 27 \\
\hline & & $\%$ & 5.3 & 5.3 & 2.7 & 61.9 & 18.0 \\
\hline \multirow[t]{2}{*}{3} & \multirow{2}{*}{$\begin{array}{l}\text { Female students are more likely to blame themselves } \\
\text { for a lack of success than are male students. }\end{array}$} & $\mathrm{N}$ & 21 & 114 & 9 & 6 & - \\
\hline & & $\%$ & 14.0 & 76.0 & 6.0 & 4.0 & - \\
\hline \multirow[t]{2}{*}{4} & \multirow{2}{*}{$\begin{array}{l}\text { Female students are more likely to refer to personal } \\
\text { experiences in class than male. }\end{array}$} & $\mathrm{N}$ & 19 & 103 & 8 & 20 & \\
\hline & & $\%$ & 12.7 & 68.7 & 5.3 & 13.3 & \\
\hline \multirow[t]{2}{*}{5} & \multirow{2}{*}{$\begin{array}{l}\text { Male students tend to feel less comfortable in public } \\
\text { debate than female. }\end{array}$} & $\mathrm{N}$ & 10 & 15 & 6 & 88 & 21 \\
\hline & & $\%$ & 6.7 & 10.0 & 4.0 & 58.7 & 14.0 \\
\hline \multirow[t]{2}{*}{6} & \multirow{2}{*}{$\begin{array}{l}\text { Male students are more likely to be interrupted when } \\
\text { they speak than female. }\end{array}$} & $\mathrm{N}$ & 9 & 11 & 16 & 75 & 29 \\
\hline & & $\%$ & 6.0 & 7.3 & 10.7 & 50 & 19.3 \\
\hline \multirow[t]{2}{*}{7} & \multirow{2}{*}{$\begin{array}{l}\text { Female students are more likely to make one-time } \\
\text { contributions and not speak again than male. }\end{array}$} & $\mathrm{N}$ & 35 & 85 & 7 & 23 & - \\
\hline & & $\%$ & 23.3 & 56.7 & 4.7 & 15.3 & - \\
\hline
\end{tabular}




\begin{tabular}{|l|l|l|l|l|l|l|l|}
\hline 8 & Male students are more likely to phrase their comments & $\mathrm{N}$ & 14 & 16 & - & 108 & 12 \\
\cline { 3 - 8 } & in a hesitant manner than female. & $\%$ & 9.3 & 10.7 & - & 72 & 8.0 \\
\hline 9 & $\begin{array}{l}\text { Female students are less likely than male students to } \\
\text { shape the agenda of the discussion. }\end{array}$ & $\mathrm{N}$ & 30 & 92 & 8 & 7 & 13 \\
\cline { 3 - 9 } & $\%$ & 20.0 & 61.3 & 5.3 & 4.7 \\
\hline
\end{tabular}

Further, Table 6 demonstrates that most of respondents (68.7\%) believe that female students are more likely to refer to personal experiences in class than male. Similarity, female students tend to feel more comfortable in public debate than male students do (58.7\%). Half of respondents believe that male students are less likely to be interrupted when they speak than female students. Most respondents (72\%) believe that female students are more likely to phrase their comments in a hesitant manner than male students. About $57 \%$ of respondents perceive that female students are more likely to make one-time contributions and not speak again like male students (item 7). As the same time female students are less likely than male students to shape the agenda of the discussion $(61.3 \%)$.

\subsection{Discussion}

Mainstreaming perceptions and practices to promoting socialization at higher education level are identified and analyzed. University play an important role in raising the socialization and development attitude of a student by providing a stimulating, motivating and encouraging environment which indirectly results into good and higher gender socialization and development ([16]; [17]).

Most of University students are in the age group of 21 to 25 years which implies that they are young, they want to know everything even that is not good for them, free from family control and enjoy with different group of people and new to the university environment. As a result, they want to try new things like chewing khat, going to night club and get entertained in the tourist places. Moreover, some unethical and immoral men who have better economic income such as older men in Amharic "Shuger Dady" for transactional and transgenerational sexual malpractices outside the university is becoming the major negative factor that impacts the performance of young students.

This is also a major factor for wasting or killing students' reading and study time and using them as temporary sex mate. Sadly, University gates are becoming destinations of such stupid activities. On the other hand, students who are economically better but were under close family control before joining the university, want to enjoy with different bodies by going to various unnecessary places which are mentioned above and also consider doing this kind of activities as a symbol for modernization.

Responses showed that gender issues are not given as such attention at higher education particularly at university level. It was however evident from interviews held that the issues are not dealt with in depth, but just as topics minor. One respondent said "we look at these issues in passing as we have other major topics to cover." On time put aside for the teaching of gender issues, most respondents showed that they were not able to specify the real number of hours as they are issues infused within other issues.

Lack of awareness on the importance of inclusion of gender issues in university is to the whole gender equity and equality debate. Some lecturers showed surprise as they had never thought gender education was of importance in university. This showed that gender issues are not thought of with the seriousness they deserve in the implementation stage of policy.

Besides the provision of guidance and counseling, different trainings, female and male students to teacher relationships also plays significant roles in gender socialization and development. Teachers play significant role in socialization. Particularly if teachers have positive attitudes towards gender socialization and development are sensitive in the classroom, students will be encouraged to learn. Provision of guidance and counseling service for students in the university is very crucial for their success in their academic and non-academic endeavors as university students are new for the environment, free from family control and they face a number of problems such as economical, social, academic and personal.

University and department placement of students' play a key role in their future life adjustment and their success in a given field of study. In most cases, if both female and male students are placed based on their interest in the university and department, they can be successful in academic endeavors in particular and in their future life in general, and vice versa. The majority of respondents agreed university and department placement of students based on their interest should be mandatory, it has a positive effect on students' gender socialization and development and otherwise vice versa. Students placed without their choice faces problems such as lack of interest in the university's environment and this makes them reluctant to attend their lesson and since they are placed too far from their parents they are suffering from home seeking of their families (particularly when they were freshman students). Assertive training, which is a behavioral technique, helps students to develop the necessary social skills to manage interpersonal and academic situations more effectively, and to feel better about themselves. 
It was clear that students' lack adequate knowledge to address gender issues in universities. Most said that their experience of university does not really prepare them adequately for the gender challenges they face as individuals and also those faced by their students and the communities they find themselves in. Instructor respondents showed that they have not been adequately prepared to tackle gender based challenges in their profession. Moreover, female and male students equal participate in different clubs help them to share their experiences, to help each other etc. The majority of respondents agreed to the effect of co-curricular trainings and specifically females participation in different clubs on their socialization and development are important. In this regard, interview result also asserted that if students participate in different trainings, they can develop their self-confidence and well aware how to manage themselves with new environment.

The other problem faced by students was found to be economic constraint. Economic constraints seriously affect students' socialization and development, which spans from the very limitation of purchasing the necessary educational materials to those affecting their relationship and health. Parental status also has effect on gender socialization and development. Students from poor families failed to fulfill necessities such as socialization, education materials, cosmetics, recreation, etc. As a result, to get away from such trap they may be engaged in different immoral, and risky engagements such as sexual affairs and expose themselves to irreversible problems including HIV/AIDS and unwanted pregnancy and consequently they dropped out of the university and have extended consequences in their future life. The report from interviewed gender, management experts, teachers and confirmed that some students are exposed to such risky situations. On the contrary, females' who are from poor economic background parents have low self esteem as well as feel inferiority.

Students' expectations of their university socialization and career prospects play significant roles in their persistence at university. Students' self-image, self-presentation and self perception on their socialization and development is lower and they perceive themselves they are academically weak and they believe that "we can ' $t$ '. Due to this they cannot use their effort as well as develop dependency on others .As demonstrated from the responses, the majority of respondents, agreed on the effect of students self perception on their socialization and development.

Educated parents would perceive the need of students' education in a better way than those who are not educated. Educated parents might also facilitate the girls' learning at home, encourage, continuous follow up and motivate them to socialization, score better academically and development. The analysis of data here in this study further confirmed. The lion share of respondents indicated that the level of parental education highly affect the socialization and academic performance of students. [11] suggested that females' and males 'socialization and education is more strongly and adversely affected by parents who are illiterates than literates.

[2] gave the following example:

... a teacher calls on a female student, looks around the same area and then continues questioning the students around the girl, all of whom are female. When the teacher refocuses to a section of the classroom where boys are seated, boys receive the series of questions. And, because boys are more assertive, the teacher may interact with them longer. ( $p .342)$

This statement reflects the effects of an important gender equity issue which is that, feedback given to boys and girls by teachers can result in a greater tendency in girls to perceive negative feedback as a reflection of their inabilities [4]. For example, males and females perceive feedback and achievement differently. Females more often attribute success in math to luck rather than skill [23]. Girls interpret their problems with math as personal failures while boys tend to project it more as a problem with the subject matter itself. As females interpret problems in mathematics as personal failures, it has a negative effect on their self-esteem [3]. This subtle gender bias has two major effects on students: (1) it creates disparity in the levels of confidence and self esteem, and (2) females tend to avoid areas of mathematics and science. The following information supports the idea that feedback from teachers influence disparity in students' their self-esteem, self-image, self-presentation and enrollment. A student's persistence is affected by the encouragement from the teacher. Studies indicate that educators have the potential to influence students' confidence [23].

According to [9], gender bias may have the following negative effects: (1) it further reinforces existing gender stereotypes, (2) students may perceive the females as receiving preferential treatment from instructors, (3) may create hostility between the genders, (4) because some instructors may be afraid of male students, sending them to someone else to receive discipline may reduce the teachers' authority and stature in the classroom, (5) students observing their peers not receiving discipline may become less responsible for their own actions, and (6) instructors may avoid punishing females for fear they will become upset and cry.

Instructors often incorporate application strategies to ensure that their students receive practical learning experiences. However, such exercises can create disparity between the sexes if instructors unconsciously limit students because of bias. For example, instructors are likely to give male students directions on how to do a task, but they have a tendency to perform tasks for females [13]. The result of this type of bias is 
that males develop independence as they solve problems for themselves while females become dependent on others to assist them. Girls are less persistent at solving problems and more likely than boys to exhibit learned helplessness. However, high achieving boys receive more teacher approval and active instruction than low achieving boys. Studies show that males are more assertive than females in decision-making; however, females demonstrate assertiveness when they feel self-confident. Pearson cited in [3] stated:"

... women may be unassertive in problem-solving because they do not have high regard for their own ability to perform or to contribute to the specific topic under discussion; however, when they have confidence in their ability to contribute or add to the discussion, they demonstrate assertiveness" (p. 183).

A instructor demonstrates subtle sex bias if he or she responds to students' assertiveness differently. Boys create more response opportunities for themselves in the classroom. For example, boys are more likely to disrupt the teacher to get attention in class [13]. Findings on research of interruption patterns and gender are not consistent. Pearson cited in [2] reported that some studies indicate that male's interrupt others more than females do and other studies indicate there is no difference in interruption patterns between the sexes.

Instructors call on males more frequently and allow them to dominate in discussions, in problemsolving experiences and sometimes in the use of classroom materials [13]. According to Singer and Stake cited in [8], males' self-esteem and feeling of competence in a general sense are related to participation and selfperceived ability. Meanwhile, females continue to view as an activity for males. Instructors also unconsciously permit sex bias by allowing females to use qualifying statements. [13] reported that females tend to initiate their ideas with less confident statements such as "I'm not sure this is right. ..." This is an example of what is known as a disclaimer. Pearson cited in [9] reports that disclaimers are used to weaken or disparage the speaker's statement or request.

\subsection{Conclusion}

\section{Conclusion And Recommendations}

The purpose of this study was to examine perception and issues affecting the gender socialization and development of students at higher education and to suggest possible solutions that may help to promote students.

From literature review the researcher concludes that men play a key role in bringing about gender equality and equity since, in most societies, men exercise preponderant power in many spheres of life. In a significant fraction of developing countries men have full control of economic resources and, in some cases, they can even have the final say regarding women's health and socioeconomic issues. In the developed world the unequal distribution of family care and household tasks represent a barrier for the economic success of women. Gender violence is also an important factor that deteriorates women's integrity all over the globe. Thus the transition towards a more egalitarian society requires the contribution and commitment of men. It also found out that although there are disciplines that look at issues of gender, they do not do it in depth. The researcher concluded that the issues are included to show the policy makers that they are implementing their policies. In fewer hours are devoted to the teaching of gender issues during the whole students' orientation at university.

The research has tried to identify and analyze students' perceptions, university related, socio economic socio, cultural factors and gender differences in self-image and self-presentation students socialization and development. University related factors such as university climate, academic and administrative rules and regulations, student to teacher relationship, peer pressure, participation of female students on different clubs, tutorial classes provided by the university, different supportive/co-curricular/ trainings provided by the university to female students (assertiveness, life skill, gender issues, HIV/AIDS, and reproductive health), department choice of students, provision of guidance and counseling services and lack of female role model teachers affect female students academic performance.

Socio-cultural factors which affect students' gender socialization and development include, female students self esteem of their socialization and academic performance, and family background of female students. Furthermore, socio-economic factors such as the presence of night clubs/bar, stimulants' shops, and tourist centers around the university, economic status of parents, limited employment opportunities, and female students living outside the university and becoming non café are affecting female students' academic performance.

Specifically, in this study it can be occlude in that:

- Lack of supportive trainings provided by the university, reflected in fear of failure, female students self perception on their socialization and academic performance, lack of self confidence, self-image and self-presentation towards female students' socialization and development.

- This study has examined the ways in which gender socialization and development can be applied and explained by an identity framework. While the locus of gender, mainstreaming, gendered stereotypes, and 
gendered behavior remains relatively obscure, identity theory and identity control theory can identify how and why such phenomena perpetuate.

- Identity theory's explanation for how role typologies are defined by gender and how gender is salient across multiple situations, as well as identity control theory's use of emotion as a control system both serve to provide a better understanding of why males and females experience the world in different ways.

- Educators often unintentionally perpetuate gender bias and stereotyping by what they say, do and allow in the classroom.

- Students also receive gender misconception/stereotyping messages from instructional materials such as lecture notes, examples, references, and visual aids.

- An equitable learning environment is necessary for males and females to formulate life and career decisions based on facts rather than myths and traditional expectations.

- Many aspects of identity theory and its derivatives are still in their relative infancy as theories; the application of these theories to gender, socialization, development and the family is a logical step to make the theories more robust and sociologically viable.

- Further research is needed to test the generalizations made in this study. This is especially true for work concerning the family setting and gender socialization. Much of the current research in identity theory that examines the socialization process (especially in the earliest stages of socialization) is a relatively vacant area that needs to be explored.

\subsection{Recommendation}

Following are recommendations based on the findings of this study:

1. People who lobby for gender equality and equity have not been taken as seriously as they should be especially considering the significance of this issue in the of socialization and development. There should be a perspective shift in higher education governing bodies to position the gender question in its correct perspective. The gender rhetoric should not just end on paper in policies, but there has to be a pursuance on implementation of policies in all sectors. University instructors' should also be put under the lens of gender policy analysis.

2. There is need for well-developed training in order to improve gender socialization, equality and equity through education. In order to give an opportunity to students to critically think about the gender debate and to let them understand deeply by discussing current themes about equality and equity in society, gender sensitization is imperative. This may then lead to developing awareness in teachers to think critically about the way they can teach gender content to school children depending on the level of their growth. The university should control (by effectively executing its workplace policies and collaborative work practices) the opening of hotel, stimulant shop, night/bar/ clubs around the university by collaborating with regional government.

3. The university should give recognition and rewards for well socialized and performred students to motivate others.

4. The orientation and counseling for students' by giving attention to females should be given by course instructors and relevant teaching staff through university work.

5. The university's concerned bodies should develop a system for gender socialization and development (policy or strategy) whereby students can get support from senior students, friends and instructors.

6. The university should create means of paying special attention to students from low socio-economic backgrounds, students with disabilities and joined the university to community.

7. The government should give financial/economical support for economically disadvantaged students through evidence based income generating schemes and working in collaboration with relevant partners including the Higher Education partnership forum, donors and media.

8. Educators need to be informed of how gender bias and stereotyping behaviors affect students.

9. Educators need to be made aware of gender bias and stereotyping teaching patterns. In addition they should be provided the following guidelines to help them overcome such patterns:

Guide students toward courses best suited for their interests and talents without regard to gender.

- Maintain the same expectations for boys and girls in all subject areas.

- Avoid assigning tasks on the basis of gender.

- Interact with students, both females and males equally.

- Provide females and males the same opportunities to respond in discussion.

- Ask all students higher level questions.

- Expect neatness from all students, not just the girls.

- Expect intellectual quality from all students, not just the boys.

- Try to praise and criticize students equally. 
- Discipline girls as well as boys for misbehavior in class.

- Discipline students on the basis of their misconduct rather than their gender.

- Provide equal instruction to females and males.

- Eliminate self "put-downs" by recognizing and addressing these patterns among students.

- Provide and ensure all students have equal access to learning materials and problem-solving experiences.

- Provide equal assistance to females and males.

- Even if the trend of female students' attrition rate in Adama Science and Technology University is decreasing from time to time, still female students attrition rate is present in the university and needs to do more in this area.

\section{Acknowledgements}

The researcher wishes to thank Adama Science and Technology University research and publication offices for their financial support for this project, and for their support of the affirmative action initiatives. I acknowledge the help and full participation given by all the respondents to the questionnaires, and those who took part in the interview and focus group discussions, without whom none of this work would have been possible. I thank the University for Permission to perform this work.

\section{References}

[1]. Alebachew Adem. (2001). Gender, Development and Migration Linkages in Ethiopia: Ethiopian Development

[2]. Forum vol. 2, No. 3, Institute of Development Research, A.A.U

[3]. Anderson,M \& Margaret, L.( 2003) "The social construction of gender." In Thinking about Women: Sociological Perspectives on Sex and Gender.Edited by Margaret L. Anderson. New York: Allyn \& Bacon, pp. 21-54.

[4]. $\quad$ Aizer, A., (2010). The Gender Wage Gap and Domestic Violence. American Economic Review100(4),1847-59

[5]. Burke,J\& Peter J.(2002) "Marital socialization, gender, and identity change." Paper presented at The Pacific Sociological Association, Vancouver, BC, Canada.

[6]. Burke, J \& Jan E. (2009). Identity Theory. New York: Oxford University Press.

[7]. Carter, M. J. (2013) "Advancing identity theory: Examining the relationship between activated identities and behavior in different social contexts."Social Psychology Quarterly, 203-23.

[8]. Creswell, J.W. (2009). Research design: A qualitative, quantitative, and mixed method approaches.

[9]. Third Edition. Sage Publications. Inc. Egenti, M. N., \& Omoruyi, F. E. O. (2011). Challenges of Women Participation in Continuing Higher Education Programme: Implications for Adult Women Counselling and Education. Edo Journal of Counselling, Vol 4, No 1-2.

[10]. Hendricks, C \& Oder, SA. (2010). 'Gender equality's fact or fiction?' in The African,8,4 15.

[11]. Johnsson-Latham, G. (2006), “Do Women Leave a Smaller Ecological Footprint than Men?” Swedish Ministry of Sustainable Development, Stockholm.

[12]. Johnsson-Latham, G. (2007), "A Study on Gender Equality as a Prerequisite for Sustainable Development”,Reportto the Environment Advisory Council, Sweden.

[13]. Juma, L. S. A., Simatwa, E. M. W., and Ayodo, T. M .O. (2012). Impact of family socio-economic status on girl students' academic achievement in secondary schools in Kenya: a case study of kisumu east district. Educational Research, 3(3):297.

[14]. Kawana, S .(2009). Gender and teacher education in Japan: Feminist teachers organising for change, Electronic journal of contemporary Japanese studies, Article 3 in 2009, September 2009

[15]. Levant, R, and Thomas, J.( 2014). “The gender role socialization of boys to men.” In Gender in Organizations. Edited by Ronald J. Burke and Debra A.Major. Northampton: Edward Elgar Publishing, Inc., pp. 55-72.

[16]. Makombe, F.T. and Geroy, G. (2009).Seeking Culturally attentive Career Advancement Strategies for Women: Perspectives from Zimbabwean Women. San Houston State University.

[17]. Mersha, Y., Alemayehu Bishaw, A., Asrat, A. D., and Nigussie, A. Y.(2009). The study of policy intervention on factors affecting female students' academic achievement and causes of attrition in higher learning institutions of Ethiopia. (Unpublished).

[18]. Ministry of Education, MoE (2004). Assessment of Gender Mainstreaming Practice in Some Regions, MOE, Women's Affairs Department, Addis Ababa.

[19]. Ministry of Women' s Affairs, Gender and Community Development (2007) The Zimbabwe National Gender Policy Implementation Strategy and Workplan: 2008 - 2012, Harare, Zimbabwe Government.

[20]. MoWA, Gender and Community Development Affair (2007). The Zimbabwe National Gender Policy Implementation Strategy and Workplan: 2008-2012, Harare, Zimbabwe Government.

[21]. Munroe, M. (2001). Understanding the Purpose and Power of Women. New KensingtonWhitaker House.

[22]. Rutoro, E. (2012). An analysis of the impact of socio-cultural factors on the effective implementation of gender sensitive policies in education management. A thesis submitted to the Zimbabwe Open University for the Doctor of Philosophy in Education, Zimbabwe,November 2012

[23]. Stets, J.E.(2006). “Identity theory.” In Contemporary Social Psychological Theories. Edited by Peter J.

[24]. Burke. Palo Alto: Stanford University Press.

[25]. Stets, Jan E., and Michael J.Carter. (2011). "The moral self: Applying identity theory.” Social Psychology Quarterly (74) $192-215$.

[26]. World Bank (2011) World Development Report 2012: Gender Equality and Development, The World Bank, Washington, DC.

[27]. World Bank (2006), Gender Equality as Smart Economics, World Bank World Health Organisation (WHO) (2006), Gender Equality, Work and Health: A Review of the Evidence.

[28]. Wudu, M., and Getahun, F. (2009). Trends and causes of female students dropout from teacher institutions of Ethiopia: The case of Jimma University.Ethiopian Journal of Education and Sciences. 